\title{
Vibration Control of Wind Turbines: Recent Advances and Emerging Trends
}

\section{Breiffni Fitzgerald}

\author{
School of Engineering, \\ Trinity College Dublin, \\ Ireland \\ E-mail: breiffni.fitzgerald@tcd.ie
}

\section{Biswajit Basu}

School of Engineering, Trinity College Dublin, Ireland E-mail: basub@tcd.ie

\begin{abstract}
The wind energy sector globally is expanding and developing technically at a rapid pace. Demand for renewable energy is soaring and there is a need for increasing the efficiency and design life of wind turbine structures. The concept of using approaches and techniques developed in the field of structural control for control of wind turbine vibrations is extremely attractive and topical at present. We review the contributions of work on vibration control of wind turbines. We provide an overview on the recent literature focussing on theoretical and experimental work. Passive, semi-active and active control schemes are discussed. The development of bespoke auxiliary damping systems is also discussed as are novel turbine control algorithms utilising existing pitch/generator torque/yaw control hardware.
\end{abstract}

Keywords: Wind turbine; vibration control; passive control; active control; semiactive control

\section{Introduction}

Modern horizontal axis wind turbines (HAWTs) are the largest rotating structures on Earth. The past two decades have seen exponential increases in the size of the structural components of wind turbines, Figure 1 shows this trend. At the beginning of this century the state-of-theart commercial HAWTs had rotor diameters of the order of $70 \mathrm{~m}$ and hub heights of about $80 \mathrm{~m}$ were common. Commercial HAWTs now have rotor diameters in excess of $160 \mathrm{~m}$ with hub heights greater than $100 \mathrm{~m}$ common. The reasons for this trend can be explained by considering the theoretic power available to a wind turbine form the wind resource. The available wind power is a function of the area swept by the rotor and the wind speed. 


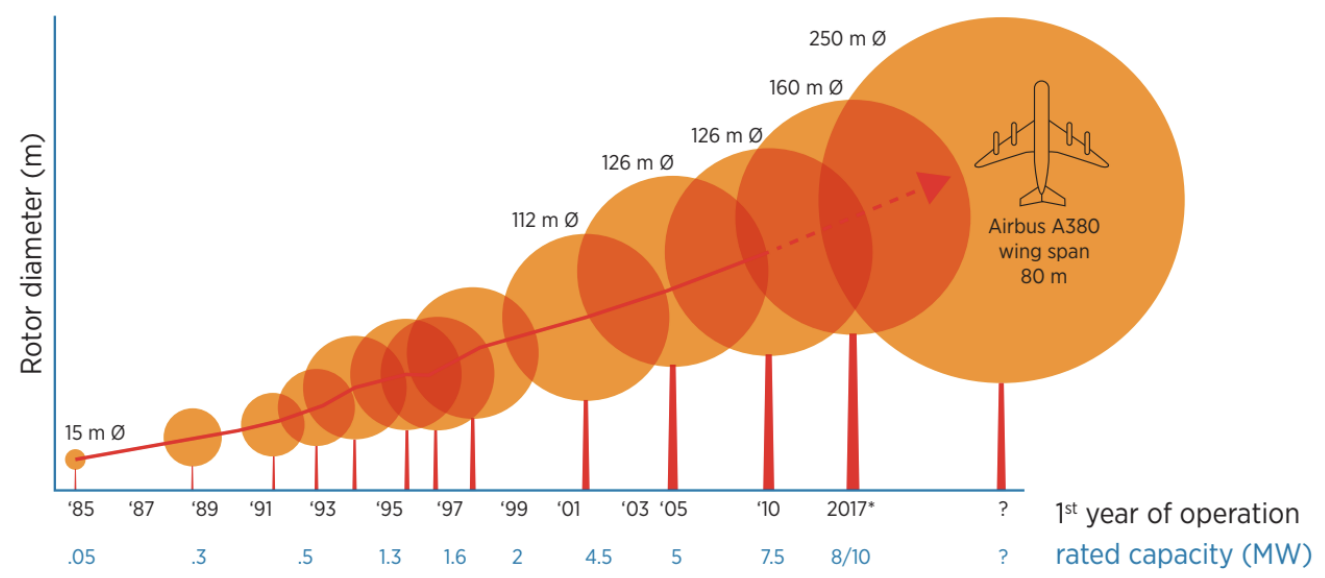

Figure 1: Growth in capacity and rotor diameter of wind turbines, 1985-2016 (Simbolotti and Kempener, 2016)

$$
P_{\text {available }}=\frac{1}{2} \rho A v^{3}=\frac{1}{2} \rho \pi r^{2} v^{3}
$$

where $\rho$ is the density of air, $A=\pi r^{2}$ is the area swept by the rotor of radius (i.e. blade length) $r$ and $v$ is the wind velocity.

Since the available wind energy increases with the square of the rotor radius it is clear that longer blades can extract more kinetic energy from the wind for power generation. Wind power availability also depends on the wind speed, increasing with the cube of the wind velocity. Increasing the hub height allows turbines to access greater wind speeds at height due to reduced wind shear effects and thus extract more energy.

As the size of the blades and towers have increased, their stiffness has reduced. Modern blades are usually manufactured from lightweight glass reinforced plastic materials and are very flexible, lightly damped structures. The towers are typically manufactured from tubular steel. The towers essentially comprise a large flexible cantilever with a concentrated mass at their top (rotor, nacelle, gearbox, etc. located here). Therefore, the towers are also very flexible, dynamically sensitive structures. These structures are subjected to substantial stochastic environmental loading, primarily from wind and waves (if located offshore). Turbulent aerodynamic loads excite the natural frequencies of the blades and the towers and can lead to substantial vibrations.

Vibration of wind turbine blades and towers is now a limiting factor in the design of even larger turbines. Wind turbine vibrations are usually described in terms of the in-plane and out-of-plane direction. Out-of-plane (flapwise) vibrations are vibrations which occur out of the blade rotation plane. In-plane (edgewise) vibrations occur in the blade rotation plane - as illustrated by Figure 2 . 


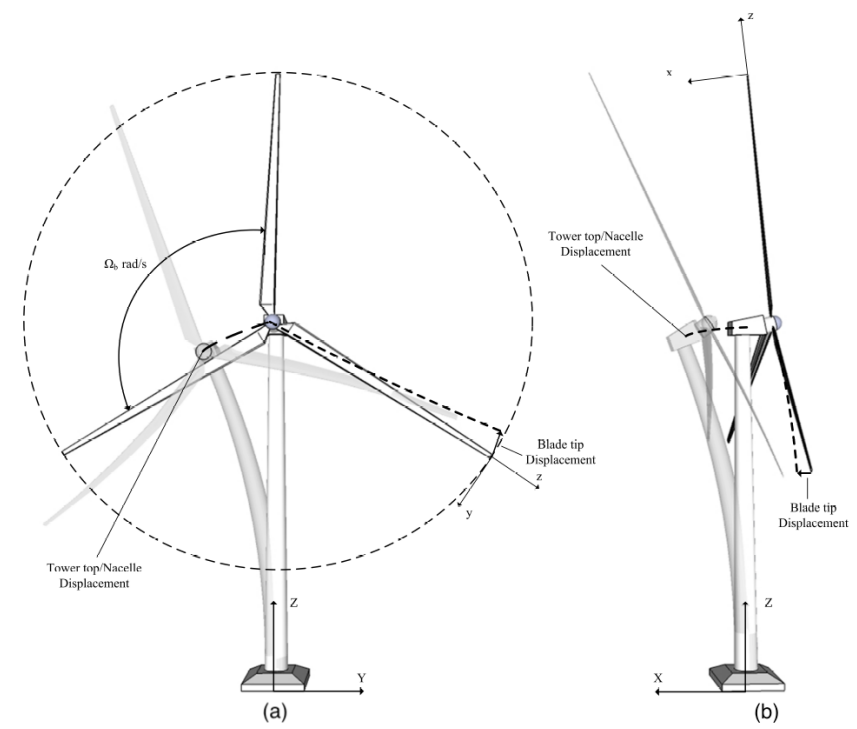

Figure 2: Wind turbine vibration: (a) In-plane, (b) Out-of-plane

It is known that out-of-plane vibrations are subject to large aeroelastic damping (Hansen et al., 2006). In the in-plane direction vibrations are dominated by the edgewise mode and have very little aerodynamic damping. Aeroelastic stability problems arising from in-plane vibrations were first noticed in the early 1990s (Thomsen et al., 2000). It has been shown that theoretically in-plane vibrations increase with blade size and wind velocity (Moeller, 1997). The appearance of turbine vibration problems has shown the wind energy industry that it is not possible to continuously scale up wind turbine designs without facing and resolving new vibratory and aeroelastic problems. The severity of vibration is obviously influenced by the structural design of the blade or tower i.e. the stiffness and mass distributions have an influence. Thus, these problems worsen as blades and towers become more flexible, lighter structures. It has been known for over a decade that large blade vibrations have a major influence on power production (Ahlström, 2006). Tower vibrations can slow down wind energy conversion to electrical power, reduce the fatigue life of the structure (Colwell and Basu, 2009) and cause malfunction of acceleration-sensitive equipment housed in the nacelle of the wind turbine, resulting in reduced annual wind turbine availability (DueñasOsorio and Basu, 2008). A significant number of tower collapses have been attributed to excessive tower vibration during strong wind events (Chou and $\mathrm{Tu}, 2011)$.

Due to these vibration problems there is now increasing interest in reducing the harmful effects of mechanical vibration on wind turbine towers in the wind energy industry. The past decade in particular has seen the application of vibration control schemes and devices to wind turbines. This is now a very active area of research. The aim of this paper is to survey the work that has taken place in this field in the past decade. Many studies, e.g. Fitzgerald and Basu (2017) and Lackner and Rotea (2011), make use of the National Renewable Energy Laboratory's fully coupled non-linear simulation code, FAST (Jonkman and Buhl, 2005). Other studies make use of Euler-Lagrange formulation to develop structural dynamic models of wind turbines, e.g. Zhang et al. (2016) and Dinh et al. (2016). The vibration control schemes that will be discussed in subsequent sections comprise: 
- Passive dampers damping devices

- Active dampers

- Semi-active dampers

- Utilisation of existing turbine controllers (pitch, generator torque, power electronics)

\section{Vibration control of wind turbines using auxiliary dampers}

Structural control involves employing techniques to suppress undesirable vibration levels in flexible structures. Although structural control is now a classical area of engineering research, applying structural control techniques to wind turbines is a relatively new and developing area of research. The wind energy industry is currently applying technologies and techniques developed in the fields of structural control and health monitoring to reduce vibrations in blades and towers. The application of structural control strategies to wind turbines is now a very active area of research. Various approaches are possible to alleviate the high levels of vibration flexible structures can experience. One such modification to the structure is the addition of auxiliary damping devices to increase the overall level of structural damping in the structure. Increasing the effective damping of a structure will lead to decreased structural motion. The damping of a structure does not relate to a unique physical phenomenon like the mass and stiffness of a structure and as such the damping of a structure cannot be engineered in the same way as these two properties. Damping is notoriously difficult to predict and quantify, the current state of the art is such that prediction closer than plus or minus 30\% is impossible until the structure is completed (Kareem and Gurley, 1996). In cases where the inherent damping is not sufficient, such as wind turbine blades and towers, supplemental damping devices may be added to the structure. Auxilliary damping is provided by these supplemental damping devices. These devices can be classified as passive, active, semi-active or hybrid.

\subsection{Passive dampers}

Passive supplemental damping devices are activated by the motion of the structure. No external force is required for the operation of a passive structural control strategy. Passive dampers have constant damping properties determined by their material and physical properties which remain fixed throughout the device's life. Their properties cannot change to reflect changes in the primary structure (e.g. damage) or changes in the environmental conditions (e.g. altered loading). As such passive control is not very robust in this context.

\subsubsection{Tuned Mass Dampers (TMDs)}

Passive control of wind turbines has received much attention from researchers. Enevoldsen and Mørk (1996) applied a passive mass damper to a wind turbine tower to reduce the dynamic response of the tower and fatigue load on the tower. The effects due to the application of passive structural control were investigated and a sensitivity analysis was performed to determine optimal designs. It was found that the application of a mass damper to a turbine tower could result in more economically efficient design. Anderson et al. (1999) considered the use of passive blade mounted dampers to eliminate edgewise stall vibration of wind turbine blades. The authors mounted a tuned mass damper (TMD) within the tip 
Vibration Control of Wind Turbines: Recent Advances and Emerging Trends

air brake of a $22 \mathrm{~m}$ blade on a $600 \mathrm{~kW}$ turbine. The dampers were retro-fitted to the blade tips at $93 \%$ of the blade length. The concept of installing dampers within blades to reduce edgewise vibrations was experimentally verified. It was found that dampers offer a low cost solution to blade vibration problems on high-wind sites. Murtagh et al. (2008) investigated the use of a passive TMD for the mitigation of wind turbine vibrations due to the alongwind forced vibration response. The simplified multi degree of freedom structural model developed is shown in Figure 3. Murtagh's model was quite a simplified multi modal model. The tower was modelled by two masses with associated springs and dashpots - the blades were similarly modelled as seen in Figure 3. An optimal tuning ratio for lightly damped structures was derived and vibration reduction was observed when a damper was placed at the top of the tower. It was found that it is feasible to use dampers for vibration suppression in wind turbines. The authors also recommended the use of active control in future research due to the time varying nature of the system parameters.

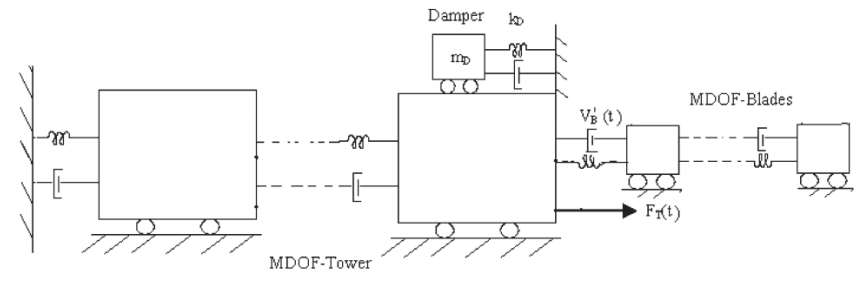

Figure 3: Schematic of wind turbine with TMD (Murtagh et al., 2008)

Lackner and Rotea (2011) incorporated two TMDs into the aero-elastic wind turbine code FAST. The TMDs were attached to the nacelle. Nacelle motion in the fore-aft and side-side directions was therefore damped. Their investigation showed that passive control can be used to improve the structural response of offshore wind turbines. The authors also recommended the use of active control in future studies and also recommended using structural control techniques to damp blade vibrations. Stewart and Lackner (2013) investigated the use of passive TMDs for load mitigation in fixed bottom and floating offshore wind turbines, the TMD was installed inside the nacelle as shown in Figure 4. Figure 4 shows the model for the fixed bottom case with a monopile foundation. This model only considers fore-aft vibrations. The tower is modeled as an inverted pendulum, with stiffness and damping modeled as a rotary spring and rotary damper at the base of the rigid body. The TMD is modeled as a mass on a linear track with a linear spring and damper. Optimum TMD parameters were developed and a genetic algorithm approach was used to find global optimum TMD parameters for different offshore platform types. Misaligned wind and wave loads were considered in this study. Numerical simulations demonstrated that tower fatigue damage reductions of up to $20 \%$ could be achieved with the passive dampers. Si et al. (2013) and Si et al. (2014) modelled and optimized passive TMDs for offshore floating spar type wind turbines. The TMDs were installed inside the nacelle and inside the spar to mitigate vibrations. A parametric study was carried out and the damper parameters were optimized for different wind/wave loading scenarios. 


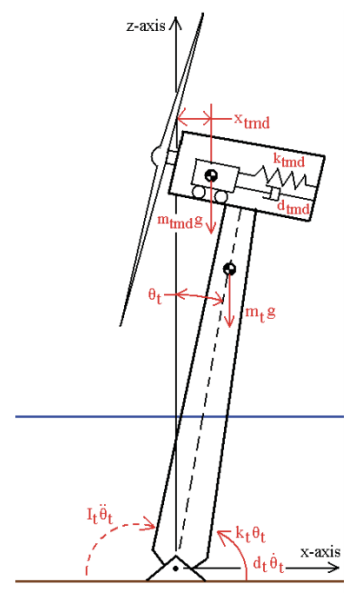

Figure 4: TMD located in nacelle of offshore wind turbine (Stewart and Lackner, 2013)

Dinh and Basu (2015) developed passive vibration schemes for spar type offshore wind turbines using single and multiple TMDs, see Figure 5 for details. Two sets of multiple TMDs were installed in the nacelle and the spar as shown in Figure 5. The TMDs in the nacelle and in the spar are modeled as single DOF systems. The goal of this work was passive control of edgewise vibrations of the nacelle/tower and the spar. It was shown that a TMD can reduce up to $40 \%$ of the nacelle sway displacement and the spar roll, and the use of multiple TMDs can achieve response reductions of up to 50\%. The influence of the spar TMD was found to be more significant than that of the nacelle TMD. In all the cases studied, the stability of the floating offshore turbine was maintained with good heave performance.
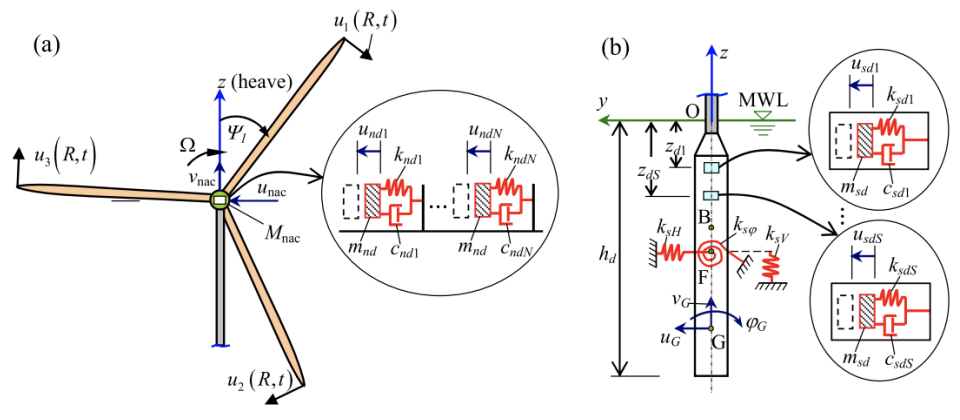

Figure 5: Control of nacelle and spar vibrations by multiple tuned mass damper (TMD); (a) Nacelle TMDs and (b) spar TMDs (Dinh and Basu, 2015)

Stewart and Lackner (2014) used optimized passive TMDs to reduce vibrations in offshore wind turbines with monopiles. In particular the effect of wind-wave misalignment was studied. Significant load reductions were achieved using the passive dampers especially for the in-plane loads when wind-wave misalignment is present.

Recently Zuo et al. (2017) used multiple passive TMDs for multi-hazard vibration control of offshore wind turbine towers. The fundamental and higher modes of offshore wind turbine towers are controlled using TMDs under multiple hazards (combined aerodynamic, 
hydrodynamic and seismic loads). The effectiveness of the proposed method is numerically investigated and promising results are reported.

\subsubsection{Tuned Liquid Column Dampers}

Colwell and Basu (2009) examined the effect of passive control on an offshore wind turbine modelled as a multi degree of freedom system under wind and wave loading. Cases of the blades lumped at the nacelle and of rotating blades were considered separately. The passive control device applied was a Tuned Liquid Column Damper (TLCD). It was found that the TLCD could achieve a reduction of up to $55 \%$ in the wind and wave-induced structural response. It was also observed that the fatigue life of the wind turbine was greatly increased by the application of the TLCD.

Mensah and Dueñas-Osorio (2014) developed TLCDs for wind turbine towers to improve the structural reliability of these components. Peak responses of wind turbine towers were reduced by up to $53 \%$ using the TLCDs. The authors showed that the use of the TLCD significantly improves the wind-induced fragility of towers. It was also shown that for equal total damper mass, a single TLCD is more effective than multiple TLCDs. The site-specific failure risk of multi-megawatt wind turbines was reduced by the use of these passive dampers.

Zhang et al. (2015) developed tuned liquid column dampers (TLCDs) for vibration control in wind turbine blades. Tuned liquid dampers were also investigated by Zhang et al. (2015) and Zhang et al. (2016) with full scale TLDs experimentally tested in a real time hybrid system, Figure 6 shows the experimental setup. The physical substructure (the TLD) was set up in a reaction frame as shown. The setup has a hydraulic actuator in the horizontal direction and a data acquisition system. The full-size TLD is made up of a closed rectangular tank, with a inner size of $1.93 \mathrm{~m}$ (length) $0.59 \mathrm{~m}$ (width) $1.2 \mathrm{~m}$ (height). Since the width of the tank is much smaller than the length, it is expected the sloshing of the water is predominately 2-dimensional. The experimental results were compared with the results from numerical simulations of the TLD-wind turbine system. The study provides strong support and useful guidelines for the application of TLDs in large wind turbines.

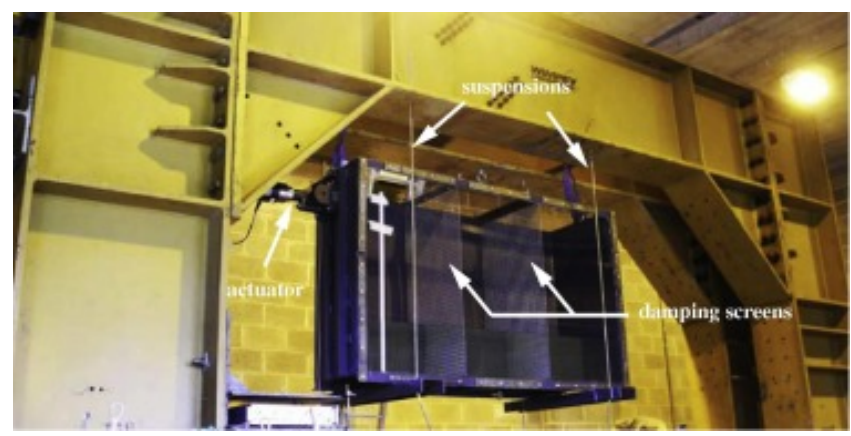

Figure 6: Experimental test setup and the physical substructure (the TLD) (Zhang et al., 2016)

\subsubsection{Other types of passive damper}

Basu et al. (2014) proposed a circular liquid damper to reduce edgewise blade vibrations. Figure 7 illustrates the schematic representation of a rotating blade equipped with a circular 


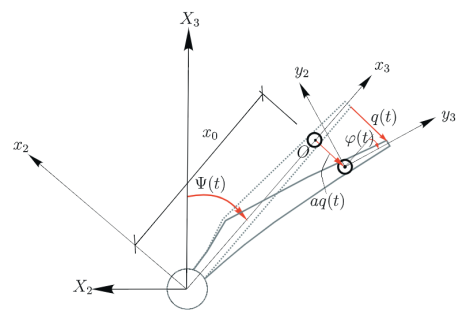

(a) Damper inside blade

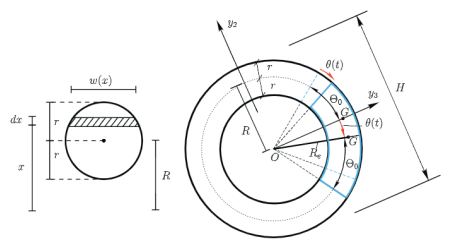

(b) Geometries of the circular liquid damper

Figure 7: Circular liquid blade dampers (Basu et al., 2014)

liquid damper. The edgewise vibration of the blade is described in the moving $x_{2}, x_{3}$ coordinate system, while the motion of the liquid inside the damper is described by another local coordinate system $y_{2}, y_{3}$ fixed to the damper. This passive damper is a variant of a liquid column damper. Due to large centrifugal accelerations in wind turbine blades, the use of these kind of oscillatory liquid dampers are feasible with a small mass ratio. The damper was optimized in a reduced order model and then incorporated into a more sophisticated 13-DOF aeroelastic wind turbine model with due consideration to the coupled blade-towerdrivetrain vibrations of the wind turbine as well as a pitch controller. Numerical results demonstrated that these dampers can effectively suppress the dynamic response of wind turbine blades.

Zhang et al. (2014) developed a novel type of passive damper to reduce large amplitude edgewise blade vibrations induced by turbulence. The author's new 'roller dampers' were very effective at controlling these vibrations and can be realised physically in many possible layouts. The damper consists of a roller rolling inside an arc track. Depending on the available space inside the hollow blade, the track may be devised in the form of a complete circle or an arc. Figure 8 shows possible layouts of the damper - a homogeneous ball, a homogeneous cylinder and a flywheel. The optimized roller damper was incorporated into a 13-DOF wind turbine model and results indicated that the proposed damper can effectively improve the structural response of wind turbine blades.

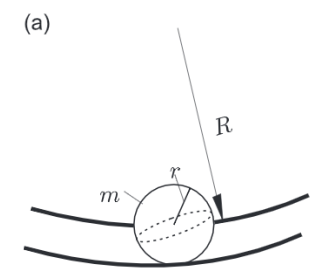

(b)

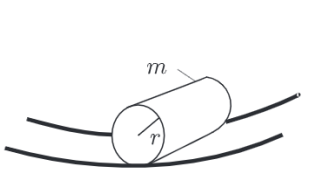

(c)

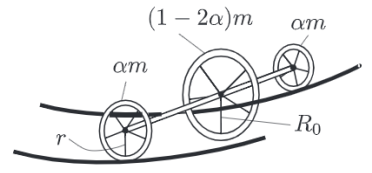

Figure 8: Possible layouts of a roller damper inside a wind turbine blade. (a) Homogeneous ball (b) homogeneous cylinder (c) a flywheel and two small rail wheels (Zhang et al., 2014)

\subsection{Active dampers}

Active dampers are 'activated' by an external force. The force is determined by a control scheme based on sensor measurements of the external disturbance and/or the structural response. Active devices differ from passive devices as they can adjust their properties to adapt to changes in the primary structure and environmental conditions. Active control 
requires a power source to enable it to perform this function. The control forces that the device applies change as the response of the structure changes. An actuator applies the control forces. A suitable control strategy must be developed to direct the actuator to apply an appropriate control force. Active control of wind turbine blades and towers has been investigated in recent years.

\subsubsection{Active TMDs}

Lackner and Rotea (2011) investigated active control of a floating barge-type offshore wind turbine using an active TMD (ATMD). A $H_{\infty}$ multivariable loop shaping active control algorithm was developed. The performance of the ATMD was compared to a passive TMD case Tower out-of-plane fatigue load reductions of approximately $10 \%$ were achieved using the passive TMD however, oad reductions of $30 \%$ or more were achieved using the proposed ATMD, at the expense of active power and large strokes. Active control was therefore shown to be a viable way to control wind turbine vibrations. Namik et al. (2013) investigated active control of floating offshore wind turbines using ATMDs. The effect of actuator dynamics was emphasised in this work. The controller improved power regulation and reduced tower fore-aft fatigue loads and the platform pitching motion.

Fitzgerald et al. (2013) proposed the use of active TMDs (ATMDs), installed inside wind turbine blades to reduce edgewise vibrations. An active control algorithm was developed using LQR to control the displacement response of the blades, and this was compared with the passively controlled system (passive TMDs) and the uncontrolled system (no dampers). Numerical simulations demonstrated the effectiveness of that active control strategy for various turbulence levels as compared with passive and uncontrolled cases. The ATMDs achieved greater response reductions than the passive TMDs in general and were shown to be feasible for a wind turbine blade particularly for higher turbulent loadings with enough room for damper stroke within the blade. Fitzgerald and Basu (2013) also investigated the use of ATMDs for wind turbine tower vibration control.

Si and Karimi (2014) proposed an ATMD to be installed at the tower top of a spartype floating wind turbine. A gain scheduling $H_{2} / H_{\infty}$ state feedback controller was implemented with the aim of load reduction. ATMDs were also used by Fitzgerald and Basu (2016) to control wind turbine tower vibrations. The importance of considering soil structure interaction in structural control of wind turbines was demonstrated. This work demonstrated that where there are uncertainties regarding the stiffness of the underlying soil medium, passive vibration control schemes for wind turbine towers may be rendered ineffective. Furthermore, it was shown that vibration control of wind turbines using LQR controlled ATMDs has a promising prospect in situations where soil parameter values are uncertain.

Fitzgerald et al. (2018) demonstrated the improved structural reliability of wind turbine towers when an ATMD is used. A gain-scheduled LQR based controller was used in this work. The authors constructed fragility curves, illustrating reductions in the vulnerability of towers to wind loading owing to the inclusion of the ATMD. Results show that the active controller is successful in increasing the reliability of the tower.

Brodersen et al. (2017) developed an ATMD for controlling tower vibrations of fixed offshore wind turbines. The controller utilizes feedback from the tower displacement and the relative velocity of the damper mass. Optimum damper parameters were derived and optimal feedback gain values determined. It was demonstrated that the ATMD can be used to further reduce the structural response of the wind turbine compared with a passive TMD 
without an increase in damper mass. This improved performance however comes at the cost of increased damper stroke.

\subsubsection{Active tendons/cables}

Staino et al. (2012) investigated the use of actuator control to mitigate edgewise vibration in wind turbine blades. The authors proposed an innovative hardware scheme which fits inside the blades to deliver the active force. Figure 9 shows the proposed system inside a hollow wind turbine blade. The active vibration control is implemented by means of two linear actuators located inside the blade. The actuators are mounted on a frame supported from the nacelle. A net control force acting on the blade tip in the edgewise direction is delivered by the actuators. The control forces are determined by a linear quadratic (LQ) based control law. The LQ regulator was compared against vibration control performance using Direct Velocity Feedback (DVF). Numerical simulations showed the effectiveness of the proposed active control scheme. In comparison with the uncontrolled response, the active control scheme can provide a reduction of $65 \%$ in the maximum blade displacement by applying a force of roughly $28 \%$ of the blade weight. The authors used a similar active control strategy to mitigate edgewise blade vibrations in cases where changes in the rotational speed, due to some grid faults, cause edgewise vibration (Staino and Basu, 2013).

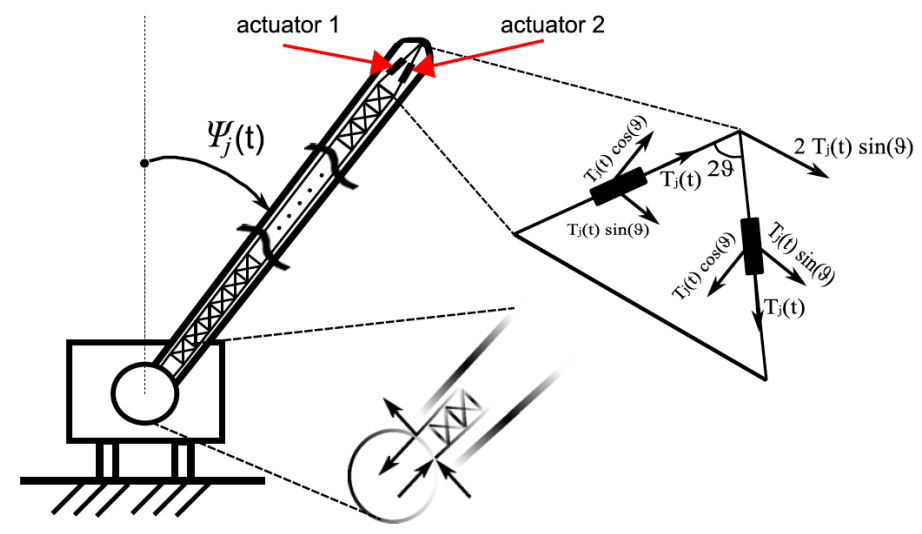

Figure 9: Active tendon inside blade to deliver active control force in edgewise direction (Staino et al., 2012)

Fitzgerald and Basu (2014) proposed a novel active damper termed the "cable connected ATMD (CCATMD)'. The new damper consists of an ATMD mounted inside the blade at a certain distance from the blade tip. A cable is attached to the ATMD on one end and is connected to the blade tip at the other end. Figure 10 shows the arrangement inside the blade. A tensile force is introduced in the cable. When the ATMD moves the cable tension at the blade tip acts at an inclined angle to the radial axis of the blade a component of which opposes the in-plane loading on the blade as shown in Figure 10. 
Vibration Control of Wind Turbines: Recent Advances and Emerging Trends 11

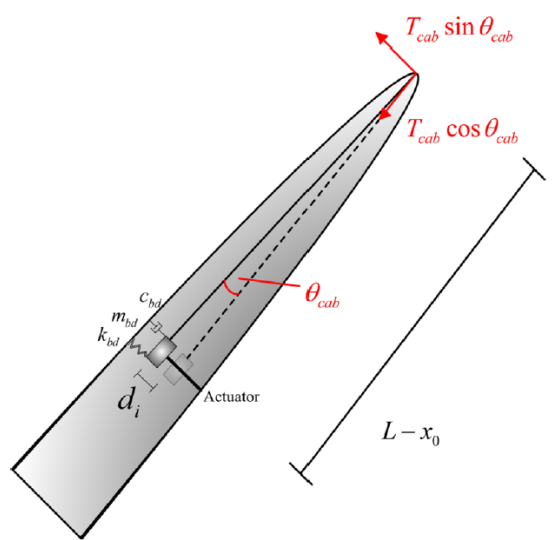

Figure 10: CCATMD arrangement inside blade (Fitzgerald and Basu, 2014)

An LQR based active control strategy was developed to control the CCATMD. The CCATMD performance was impressive - CCATMDs cable tension of $200 \mathrm{kN}$ were shown to reduce the peak-to-peak in-plane blade vibration by up to $41 \%$ (compared to the uncontrolled system) with a peak active control force requirement of $5 \mathrm{kN}$.

\subsection{Semi-active dampers}

Semi-active control attempts to combine the best features of both passive and active control systems. Semi-active devices were developed to enable the benefits of active control to be utilized whilst reducing the power required for operation of active control. In some cases it may not make economic sense to use an active device due to the large power costs. In these cases semi-active control may be used. Semi-active control uses the structure's response and a feedback feature to develop control forces. In a semi-active damper the mechanical properties of the device are varied and an external control force is not applied. The power required for operation is usually a great deal less than the power required for an active control strategy but vibration reductions may not be as significant.

\subsubsection{Semi active TMDs}

Arrigan et al. (2011) developed semi-active TMDs to control flapwise vibrations in wind turbine towers and blades. The semi-active algorithm used short time Fourier transforms (STFTs) and Hamming windowing to track the dominant frequencies in the structure's response and to tune the TMDs in real time, the algorithm schematic is presented in Figure 11. The STFT algorithm developed in this study allows the semi-active TMDs (STMDs) to be tuned in real time to the dominant frequencies in the system. A similar semiactive algorithm was used by Fitzgerald et al. (2010) for damage detection and flapwise vibration control in wind turbine blades. Arrigan et al. (2014) also developed a semi-active algorithm to mitigate edgewise blade vibrations, using semi-active TMDs. 


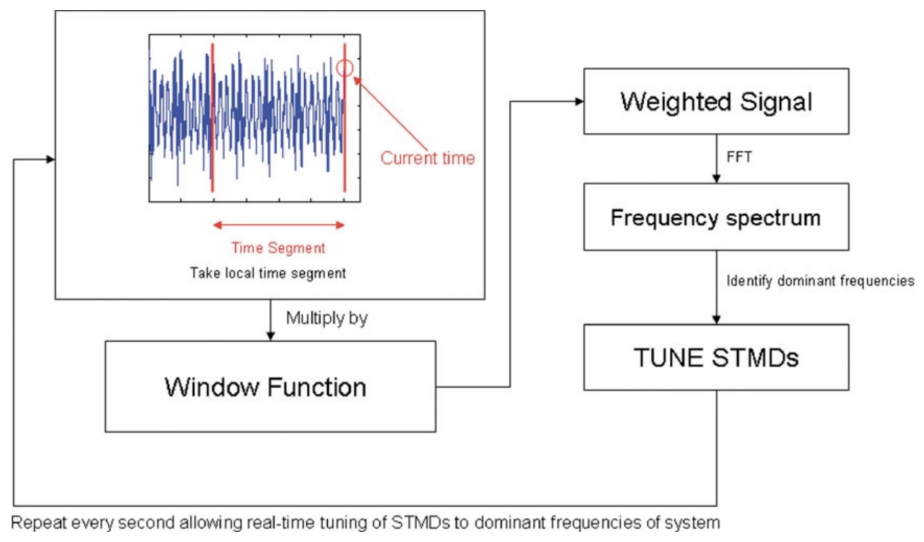

Figure 11: Semi-active control algorithm for flapwise blade vibration (Arrigan et al., 2011)

Dinh et al. (2016) developed a semi-active algorithm for vibration control of spar type floating offshore wind turbines. TMDs were installed in each blade, in the nacelle and on the spar to control in-plane vibrations. A STFT algorithm was used for semi-active control of the TMDs. The control algorithm schematic is provided in Figure 12. As can be seen from the schematic, the stiffness of the TMD spring is changed according to the instant dominant frequency of the responses and the Short Time Fourier Transform (STFT) is used to evaluate that dominant frequency. Numerical simulations demonstrated the effectiveness of the semi-active TMDs. Impressive performance improvement over passive TMDs were reported, however, this was at the cost of excessively large TMD stroke of the nacelle TMD.

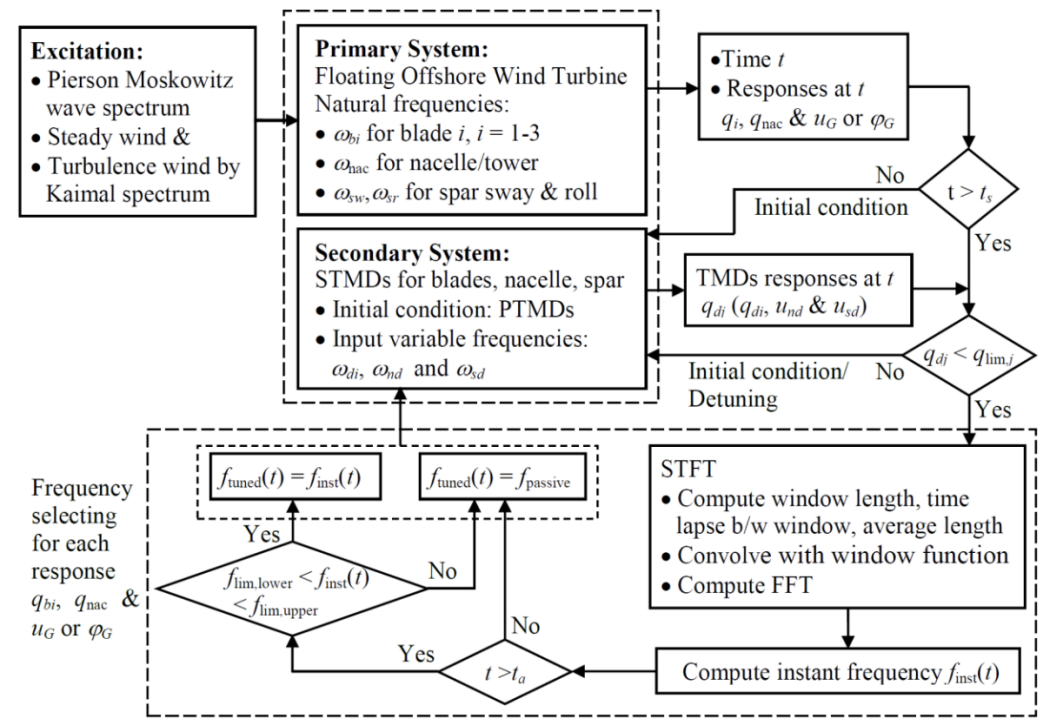

Figure 12: Semi-active control algorithm for in-plane vibration control of offshore HAWTs (Dinh et al., 2016)

Sun (2018) used semi-active TMDs to control offshore wind turbines with monopile foundations. The turbines were subjected to aerodynamic, hydrodynamic and seismic loads. 
Vibration Control of Wind Turbines: Recent Advances and Emerging Trends 13

The semi-active TMDs proposed had tunable natural frequency and damping ratio. A short-time Fourier transformation (STFT) based control algorithm is used to achieve this objective. Damage is simulated and the dampers were retuned in real-time to new dominant frequencies. Compared to passive TMDs the semi-active TMDs demonstrated an ability to control the dynamic response of the monopile offshore wind turbines under the multi-hazard environment with structural damage, whilst requiring a reduced damper stroke.

\subsubsection{Semi active TLCD}

Semi-active vibration control of wind turbines has received less attention in the literature than passive control and active control. Karimi et al. (2010) proposed a semi-active TLCD for offshore wind turbine towers. An optimal $H_{\infty}$ control algorithm was used to formulate a control law. Output feedback is utilized to avoid the dependence on the knowledge of the states of the system. In further work the authors investigated a mixed $\mathrm{H}_{2} / \mathrm{H}_{\infty}$ control algorithm for the same problem (Luo et al., 2011).

\subsubsection{MR dampers}

Caterino (2015) proposed the use of magneto-rheological (MR) dampers to semi-actively mitigate wind turbine tower vibrations. Bang bang control is used in this work. Experimental work was carried out to verify the effectiveness of the semi-active control strategy. The semi-active damper reduced the stress demand at the tower base at the cost of a slight increase in tower top displacement.

Sarkar and Chakraborty (2018) proposed a semi-active vibration control scheme for HAWT towers using MR-TLCDs. The proposed wind turbine model and the magnetorheological tuned liquid column damper is shown in Figure 13. An LQR based semiactive control law was developed to mitigate the along-wind vibration of the tower. Clipped optimality of the control force was imposed to ensure realistic MR-TLCD performance. Finally, sensitivity analysis is carried out to demonstrate the performance envelope of the proposed control algorithm for different operational scenario. Results presented in this paper clearly demonstrate that the proposed algorithm can be employed for effective along-wind vibration control of large HAWT tower.
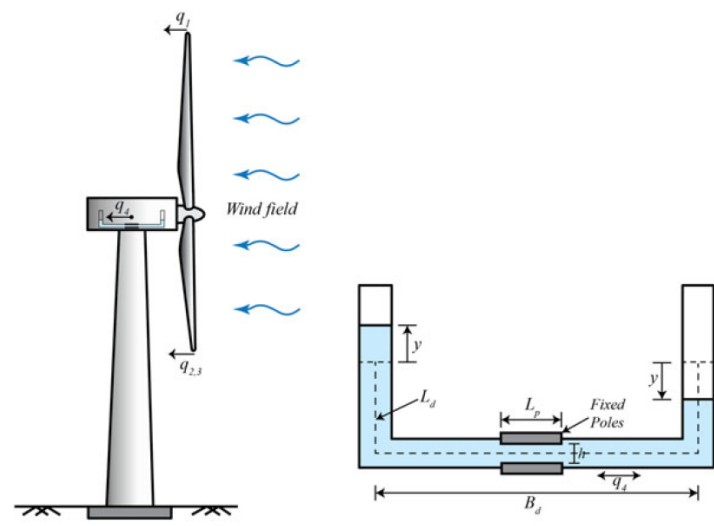

Figure 13: MR-TLCD inside HAWT nacelle/tower (Sarkar and Chakraborty, 2018) 


\subsection{Implementation issues with auxiliary dampers}

The previous sections have described the impressive results that can be achieved by installing auxiliary dampers in wind turbine blades and towers. Impressive response reductions can be achieved. However, the actual implementation of these dampers in full-scale wind turbine structures needs careful consideration of certain practical design constraints. The wind energy industry must also understand the risks, constraints, limitations and costs involved when installing these devices.

Due to their inherent simplicity, passive dampers are often the first option considered by infrastructure owners and designers. Tuned liquid dampers and liquid column dampers can be maintained relatively easily by maintaining the water level in the devices, this is very cost effective. On the other hand, in case of a TMD, maintenance and tuning are more difficult and costly. Liquid dampers are not particularly sensitive to the frequency ratio between the primary and secondary systems. Sloshing of the liquid inside the device means that for a wide range of amplitudes of oscillation damping is provided to the primary system. TMDs on the other hand require more precise tuning and do not provide a broad-banded response reduction. Liquid dampers also require no activation mechanism for their operation while TMDs are usually designed to be activated at a certain threshold acceleration. Passive dampers have the following issues that must be addressed when considering their implementation in wind turbine structures:

- Maximum damper displacement - dampers must move to oppose vibration but there are strict limits on this motion if the damper is installed inside the tower or blade.

- Number of dampers - each passive damper can only damp one eigenfrequency.

- Installation location - to be effective it would be best to install the damper at the tower top or the blade tip. However, space in both of these locations is limited.

- Mass - for a passive damper the mass ratio is crucial. However, adding a large mass to a very flexible rotating structure such as a blade or a very tall slender tower requires detailed analysis.

Semi-active or active dampers have the following issues that must be addressed when considering their implementation in wind turbine structures:

- Power source - these dampers require a power source to operate - this may be compromised at times of high winds when the damper is most needed.

- Sensor data - Many controllers proposed in the literature require full state feedback and in some cases a preview of the wind loading. In reality this will not be available to the controller due to the lack of sensor data recorded in the field. Observer design is an area where work is currently needed.

- Real-time implementation - Controllers must be able to operate in real-time. However, many proposed in the literature do not report speed of the algorithm.

- Actutaor dynamics - Many reported studies do not consider actuator dynamics. In reality there will be a time delay before the control law is implemented due to the actuator dynamics. Neglecting actuator dynamics may cause performance degradation and cause an otherwise stable control law to become unstable 
Vibration Control of Wind Turbines: Recent Advances and Emerging Trends 15

\subsection{Industry uptake of auxiliary dampers}

Many different structural control schemes have been proposed and developed by researchers in the past decade. As evidence of the impact of this research, the scientific work carried out has been translated into practice and several industries have adopted the technologies, including patenting variations of dampers for applications in wind turbines to mitigate vibrations. Dampers are now regularly installed in commercial wind turbines by two of the largest manufacturers of wind turbines, Vestas and Siemens.

Vestas have patented a method for damping wind turbine towers with a liquid damper (Ollgaard and Jensen, 2017). The damper does not need detailed tuning to the tower's natural frequency. As long as the damper mass is sufficient, it may be used for damping a range of tower sizes and heights. Vestas also patented a type of pendulum TMD for damping wind turbine tower oscillations, see Figure 14 (Ollgaard and Jensen, 2017). The damper comprises a bag of material or liquid connected to a tower component at a first lateral distance away from a tower wall. The bag is also suspended from the tower component by a first vertical distance. The height of the tower component is known such that the first vertical distance corresponds to a particular height within the tower. The first lateral distance, first vertical distance, and mass of the bag are such that the bag is configured to hit the tower wall during oscillation, in order to damp the oscillations in the wind turbine tower.

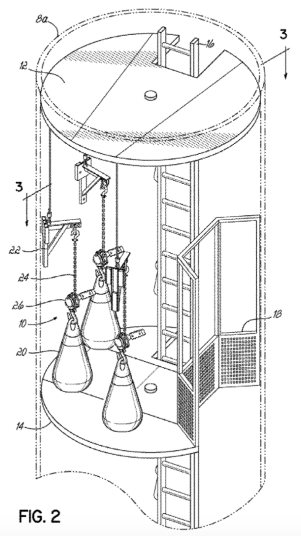

Figure 14: Vestas damping scheme for tower oscillation (Ollgaard and Jensen, 2017)

Siemens have also recently patented a liquid damper for a wind turbine tower (Jensen, 2016). The aim of the damper system is to at least partially eliminate unwanted vibration of the wind turbine resulting from wind loads. The damper system is arranged at a non-rotating part of the electric generator housed in the nacelle at the top of the tower. The configuration is shown in Figure 15. 


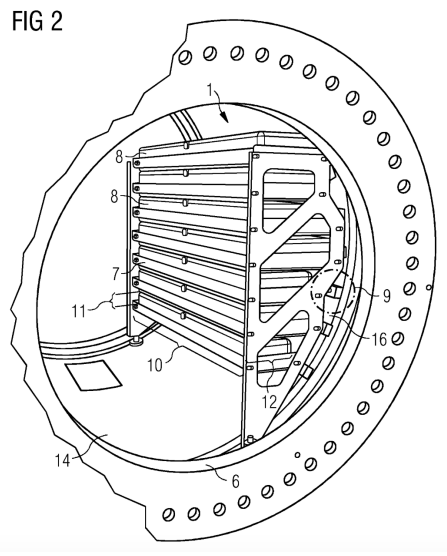

Figure 15: Siemens liquid damper configuration (Jensen, 2016)

\section{Vibration control of wind turbines using existing turbine control hardware}

Modern HAWTs are equipped with sensors, controllers and actuators to enable optimal extraction of energy from the wind. State-of-the-art wind turbine control objectives include:

- Power regulation: power maximization, power saturation, smoothing, etc.

- Rotor speed regulation: noise restriction

- Load mitigation: For reliable operation over the turbine's lifetime, the structural loads need to be kept within their design limits.

- Grid-compliance: decoupling of mechano-electrical dynamics, compliance to national grid-codes, etc.

Generally three control systems are designed to achieve these control objectives: a generatortorque controller, a full-span rotor collective blade-pitch controller and a yaw controller. The typical control architecture is shown in Figure 16. Traditionally, the closed-loop wind turbine controller consists of slightly coupled single-input-single-output (SISO) controllers. One sensor is typically connected to one actuator. The main measurements obtained from sensors are the yaw misalignment and the generator speed. The yaw misalignment is used by the yaw controller to align the turbine with the main wind direction and thereby to maximise the energy capture of the individual wind turbine. The generator speed is used by the torque controller in Region II (where the wind speed is above the cut-in wind speed but below the rated wind speed) and is also the input to the collective blade pitch controller in Region III (where the wind speed is above the rated wind speed but below the cut-out wind speed). 


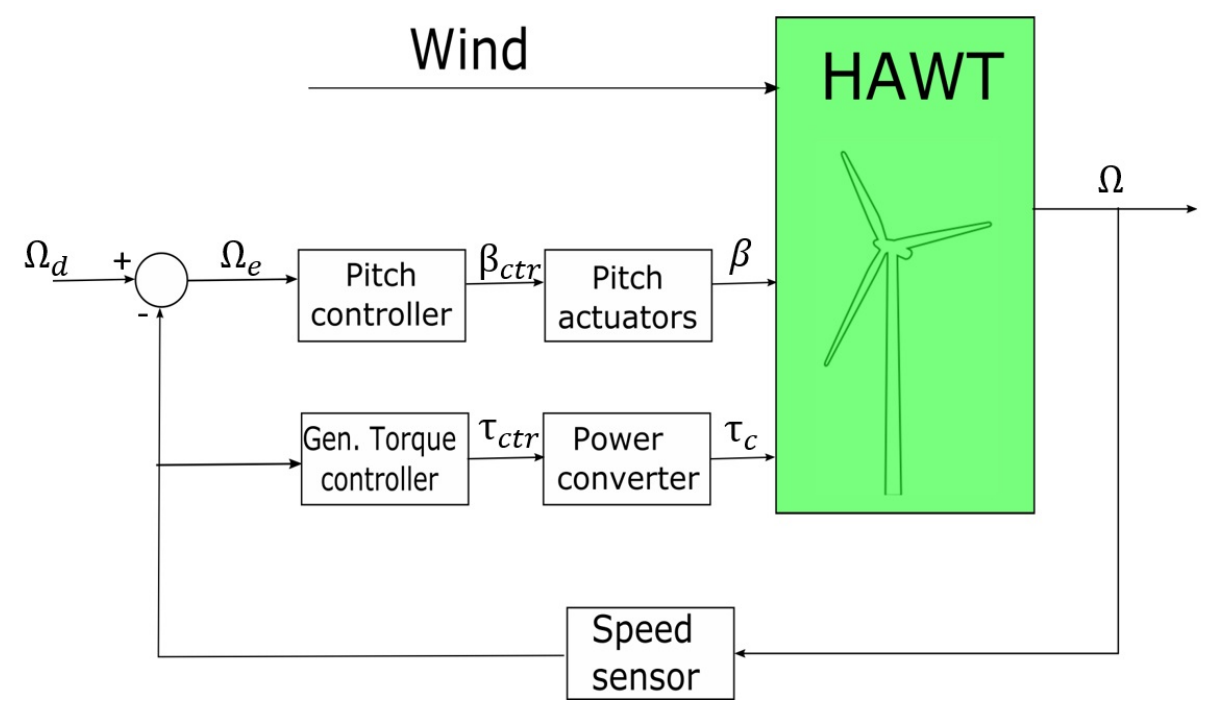

$\Omega=$ turbine rotor speed

$\Omega_{d}=$ desired rotor speed

$\beta_{c t r}=$ pitch controller signal

$\beta=$ pitch control command

$\tau_{c t r}=$ torque controller signal

$\tau_{c}=$ generator load torque

Figure 16: Conventional modern HAWT control architecture

In recent years researchers have investigated novel control algorithms for vibration control of wind turbines which utilize some or all of this existing control hardware. The clear benefit of this concept is the mitigation of vibrations without the costly installation and design of auxiliary dampers in blades and towers. Utilizing existing control hardware eliminates virtually all of the implementation issues associated with the installation of dampers.

\subsection{Individual pitch control (IPC) methods}

Bossanyi (2003) published a seminal paper on the concept of using individual pitch control (IPC) for load reduction. As remarked in Staino and Basu (2015), it is often not acknowledged in the wind energy literature that load control and vibration control are two sides of the same coin. Since Bossanyi (2003) and Bossanyi (2005), many works have used blade pitch control to reduce blade vibration. Namik and Stol (2010) investigated IPC of floating offshore wind turbines.

The authors presented three types of controllers: a collective blade pitch (CBP) classical controller as a baseline controller using PI, a CBP state space controller and an individual blade pitch (IBP) controller. The proposed IBP controller utilized individual blade pitching to improve power output and reduce platform motions in above rated wind speed region. LQR was used to used to do this. Rotor speed regulation was also achieved. Turbine vibrations and fatigue loads were reduced; tower side-side fatigue loads were reduced by 39\%. Namik and Stol (2011) also developed IPC for offshore wind turbines supported on barge and tension leg floating platforms. Individual blade pitch state space control and disturbance accommodating control (DAC) that reject wind speed perturbations were applied in the above rated wind speed region. Large tower vibration reductions were achieved with small rotor speed error. Schuler et al. (2013) proposed an $\ell_{1}$ control scheme for multivariable pitch control scheme. IPC was used to decrease the blade root bending moment which improved the fatigue life of blades. Compared to classical collective and individual pitch control, a significant vibration reduction was achieved without appreciable 
losses in power production. Namik and Stol (2013) proposed an IPC strategy for spar type floating offshore wind turbines. Multi-objective linear state feedback controllers were developed with the aim of regulating power generation and stabilising the pitch and roll of the turbine platform. The controller was able to reduce tower fore-aft and side-side vibrations and regulate rotor speed with small error. Cheon et al. (2014) developed a disturbance accommodating pitch controller with the dual aim of regulating the rotor speed and reducing blade vibration. Wind inputs were treated as persistent disturbances in the controller. Simulations demonstrated impressive results under the condition of stochastic wind inputs and noise corrupted sensor signals. The proposed controller achieved significant vibration reductions for the flapwise blade case. Nonlinear model predictive control was proposed by Schlipf et al. (2013) to reduce aerodynamic loads (and hence vibration) on wind turbine towers and blades. Wind predictions provided by LIDAR were utilized in the optimization problem to achieve as well as to limit the pitch rates and regulate the rotor speed. The existing wind turbine pitch architecture was used to implement the control strategy and impressive vibration reductions were achieved in numerical simulations. Novel PI controllers have been developed with the aim of load (vibration control) and power regulation by Gao and Gao (2016) and Ren et al. (2016) (nonlinear). Yuan and Tang (2017) developed an adaptive pitch control scheme with disturbance rejection and load mitigation capability. The controller's aim was to reduce loads (and hence vibrations) on wind turbines operating in high wind speeds. The controller makes a trade-off between the maximum energy captured and the load induced. The blade flapwise vibration load was reduced at a slight expense of optimal power output. Fitzgerald et al. (2019) developed an individual blade pitch control strategy with the objective of reducing blade vibration. A wavelet based LQR control algorithm was proposed. The proposed control algorithm does not require a priori choice of the weights as in the classical case and calculates the gains using the weights based on the response characteristics in real time. Numerical simulations demonstrated significant reduction in the out-of-plane response of the blades as compared with standard LQR or industry standard proportional integral (PI) controllers, at the expense of minor increases in rotational speed variability and increased pitch actuator usage.

\subsection{Generator torque control}

Generator torque control has been investigated by some researchers for vibration control. Zhang et al. (2014) proposed to control lateral tower vibrations in offshore wind turbines using active generator torque. The interaction between the generator torque and the lateral tower vibration are presented in a generalized manner. A simple active control algorithm was proposed based on active generator torques with feedback from the measured lateral tower vibrations. Numerical simulations demonstrated that by using active generator torque control, lateral tower vibrations can be significantly mitigated for both gear-driven and direct-driven wind turbines, with modest influence on the smoothness of the power output from the generator.

\subsection{Control using power electronics devices}

Power electronics devices have also been used to provide vibration control to wind turbine components. Basu et al. (2014) modelled wind turbine mechanical and structural vibrations due to electrical grid faults. The authors proposed mitigating these vibrations using flexible alternating current transmission systems (FACTS) devices. Numerical simulations revealed that electrical disturbances can cause substantial mechanical/structural vibrations, 
Vibration Control of Wind Turbines: Recent Advances and Emerging Trends 19

in particular, the occurrence of severe vibrations due to voltage sags may compromise safe operation of the overall plant. FACTS devices were successfully able to mitigate vibrations due to electrical faults, and they can be conveniently applied to stabilize the generator shaft speed, drivetrain oscillations, edgewise blade vibrations and tower responses. Staino et al. (2014) studied the application of Unified Power Quality Conditioner (UPQC) as an effective means of suppressing gird fault induced vibrations. UPQC devices were successful in mitigating vibrations due to electrical faults.

\section{Conclusions}

The available literature on vibration control of wind turbines has been surveyed. The use of auxiliary dampers (passive, active and semi-active) has been reviewed. Active pitch control, generator torque control and control using power electronics devices has also been discussed. Details on some of these controllers, including some features of their hardware/software/key results, has been presented.

A great many studies have investigated the use of auxiliary damping devices to mitigate vibrations in wind turbines. The wind energy industry has recently begun to implement some of these controllers in their wind turbines. Passive devices (TMDs and liquid dampers) are now routinely installed in wind turbine towers by Vestas and Siemens. The studies have shown that response reductions of up to 50\% may be achieved if multiple passive dampers are employed. Many novel hardware schemes (e.g. active tendons, cable connected dampers, etc.) have been proposed by researchers and the vibration control performance of these devices is very impressive with possible response reductions of up to $65 \%$. Novel control algorithms have also been proposed. However, the industry has been slow to date at incorporating semi-active or active auxiliary dampers.

\subsection{Possible future work}

Following this review certain areas have been identified that require further investigation either because the area has been unexplored or the literature available on the topic is sparse. These areas primarily focus on the dynamics and control of wind turbines. These areas are listed below in no particular order of priority.

- Holistic dynamic modelling of the wind turbine - the dynamic model of the wind turbine must be coupled with the generator and grid dynamics. It has been shown by Staino et al. (2014) that the dynamics of the electrical grid can have a significant impact on the dynamics and structural response of a wind turbine. However, few studies in the literature couple the wind turbine structural model to a grid model. It will be important in future studies to couple the electrical and mechanical sub-systems of the wind turbine and study the dynamics in the context of the wind farm and the grid.

-Wind farm effects - although the vast majority of the studies focus on isolated wind turbines, most wind turbines are situated in large wind farms. Wind turbines interact with the other turbines in the farm via the wake that travels downstream of their rotor. Wakes in general increase the turbulence in the wind. The formation of these wakes, the increased atmospheric turbulence and its effects on the dynamics of the wind turbine must be investigated. Controllers must be designed to take these effects into account. 
- Incorporating sensor data in design of controllers - There are two different remote sensing methods for wind measurements: LiDAR (Ligth Detection And Ranging) and SoDAR (Sound Detection And Ranging). The potential of LiDAR and SoDAR wind-wave measurements has not been investigated extensively. A controller combined with LiDAR-SoDAR wind-wave measurements has the potential of greatly optimizing the long-term as well extreme event performance of the turbines. Investigation into optimized control algorithms is recommended. These control algorithms will be generally dictated by design requirements and innovative algorithms can help in optimizing the design.

\section{Acknowledgement}

We wish to state that we do not intend to entirely represent the entire research community in the wind turbine structural control field. This is presently a very active field. There are many different activities ongoing and large numbers of groups currently working at universities, research centres and industries, which we could not possibly completely capture in this article.

This research is funded in part by the Sustainable Energy Authority of Ireland, under Grant No. RDD/213. The funding is gratefully acknowledged.

\section{References}

Ahlström, A. (2006) 'Influence of wind turbine flexibility on loads and power production', Wind Energy, Vol. 9, No. 3, pp.237-249.

Anderson, C. and Heerkes, H. and Yemm, R. (1999) 'The use of blade-mounted dampers to eliminate edgewise stall vibration', EWEC-CONFERENCE, pp.207-211.

Arrigan, J. and Huang, C. and Staino, A. and Basu, B. and Nagarajaiah, S.,(2014) 'A frequency tracking semi-active algorithm for control of edgewise vibrations in wind turbine blades.', Smart Structures and Systems, Vol. 13, No. 2, pp.177-201.

Arrigan, J. and Pakrashi, V. and Basu, B. and Nagarajaiah, S. (2011) 'Control of flapwise vibrations in wind turbine blades using semiâtłactive tuned mass dampers.', Structural Control and Health Monitoring, Vol. 18, No. 8, pp.840-851.

Basu, B. and Zhang, Z. and Nielsen, SRK. (2014) 'Damping of edgewise vibration in wind turbine blades by means of circular liquid dampers', Wind Energy, Vol. 19, No. 2, pp.213-226.

Basu, B., Staino, A. and Basu, M. (2014) 'Role of flexible alternating current transmission systems devices in mitigating grid faultâEłinduced vibration of wind turbines.', Wind Energy, Vol. 17, No. 7, pp. 1017-1033.

Bossanyi, E.A. (2005) 'Further load reductions with individual pitch control. ', Wind Energy, Vol. 8, No. 4, pp.481-485.

Bossanyi, E.A. (2003) 'Individual blade pitch control for load reduction.', Wind Energy, Vol. 6, No. 2, pp. 119-128. 
Vibration Control of Wind Turbines: Recent Advances and Emerging Trends 21

Brodersen, M.L. and Bjørke, A.S. and Høgsberg, J.,(2013) 'Active tuned mass damper for damping of offshore wind turbine vibrations', Wind Energy, Vol. 20 , No. 5, pp. 783-796.

Caterino, N. (2015) 'Semi-active control of a wind turbine via magnetorheological dampers.', Journal of Sound and Vibration, Vol. 345, pp.1-17.

Cheon, J., Kwon, S. and Choi, Y. (2014) 'Design of a pitch controller using disturbance accommodating control for wind turbines under stochastic environments.', In 2014 IEEE 23rd International Symposium on Industrial Electronics (ISIE), June 2014, pp.2572-2577.

Chou, JS. and Tu, WT. (2011) 'Failure analysis and risk management of a collapsed large wind turbine tower', Engineering Failure Analysis, Vol. 18, No. 1, pp.295-313.

Colwell, S. and Basu, B. (2009) 'Tuned liquid column dampers in offshore wind turbines for structural control', Engineering Structures, Vol. 31, No. 2, pp.358-368.

Dinh, VN. and Basu, B. (2015) 'Passive control of floating offshore wind turbine nacelle and spar vibrations by multiple tuned mass dampers', Structural Control and Health Monitoring, Vol. 22, No. 1, pp.152-176.

Dinh, V.N. and Basu, B. and Nagarajaiah, S. (2016) 'Semi-active control of vibrations of spar type floating offshore wind turbines. ', Smart Structures and Systems, Vol. 18, No. 4, pp.683-705.

Dueñas-Osorio, L. and Basu, B. (2008) 'Unavailability of wind turbines due to wind-induced accelerations', Engineering Structures, Vol. 30, No. 4, pp.885-893.

Enevoldsen, I. and Mørk, KJ. (1996) 'Effects of a vibration mass damper in a wind turbine tower', Journal of Structural Mechanics, Vol. 24, No. 2, pp.155-187.

Fitzgerald, B. and Basu, B., . (2017) 'A monitoring system for wind turbines subjected to combined seismic and turbulent aerodynamic loads.', Structural Monitoring and Maintenance, Vol. 4, pp.175-194.

Fitzgerald, B. and Basu, B. (2013) 'Active tuned mass damper control of wind turbine nacelle/tower vibrations with damaged foundations.', Key Engineering Materials, Vol. 569, pp.660-667. Trans Tech Publications.

Fitzgerald, B. and Basu, B. and Nielsen, S.R.K. (2013) 'Active tuned mass dampers for control of in-plane vibrations of wind turbine blades. ', Structural Control and Health Monitoring, Vol. 20, No. 12, pp.1377-1396.

Fitzgerald, B. and Basu, B. (2014) 'Cable connected active tuned mass dampers for control of in-plane vibrations of wind turbine blades.', Journal of Sound and Vibration, Vol. 333, No. 23, pp.5980-6004.

Fitzgerald, B. and Arrigan, J. and Basu, B. (2010) 'Damage detection in wind turbine blades using time-frequency analysis of vibration signals.', The 2010 IEEE International Joint Conference on Neural Networks (IJCNN), IEEE, pp.1-5.

Fitzgerald, B. and Sarkar, S. and Staino, A. (2018) ' Improved reliability of wind turbine towers with active tuned mass dampers (ATMDs).', Journal of Sound and Vibration, Vol. 419, pp.103-122. 
Fitzgerald, B. and Basu, B. (2016) 'Structural control of wind turbines with soil structure interaction included.', Engineering Structures, Vol. 111, pp.131-151.

Fitzgerald, B., Staino, A. and Basu, B. (2019) 'Wavelet-based individual blade pitch control for vibration control of wind turbine blades.', Structural Control and Health Monitoring, Vol. 26, No. 1, p.e2284.

Gao, R. and Gao, Z. (2016) 'Pitch control for wind turbine systems using optimization, estimation and compensation. ', Renewable Energy, Vol. 91, pp. 501-515.

Hansen, MH. and Thomsen, K. and Fuglsang, P. and Knudsen, T. (2006) 'Two methods for estimating aeroelastic damping of operational wind turbine modes from experiments', Wind Energy, Vol. 9, No. 1-2, pp.179-191.

Jensen, D.K. (2016) 'Tuned liquid damper of a wind turbine. ', U.S. Patent 9,234,505, January 2016

Jonkman, JM. and Buhl, ML. (2005) 'FAST userâŁ ${ }^{\mathrm{TM}}$ S guide', National Renewable Energy Laboratory, Golden, CO, Technical Report No. NREL/EL-500-38230

Kareem, A. and Gurley, K. (1996) 'Damping in structures: its evaluation and treatment of uncertainty', Journal of wind engineering and industrial aerodynamics, Vol. 59, No. 2-3, pp.131-157.

Karimi, H.R. and Zapateiro, M. and Luo, N. (2010) 'Semiactive vibration control of offshore wind turbine towers with tuned liquid column dampers using $H_{\infty}$ output feedback control.', 2010 IEEE International Conference on Control Applications, IEEE, pp.22452249.

Lackner, MA. and Rotea, MA. (2011) 'Passive structural control of offshore wind turbines', Wind Energy, Vol. 14, No. 3, pp.373-388.

Lackner, MA. and Rotea, MA. (2011) 'Structural control of floating wind turbines', Mechatronics, Vol. 21, No. 4, pp.704-719.

Luo, N. and Bottasso, C.L. and Karimi, H.R. and Zapateiro, M. (2011) 'Semiactive control for floating offshore wind turbines subject to aero-hydro dynamic loads.', International Conference on Renewable Energies and Power Quality (ICREPQất $\left.{ }^{\mathrm{TM}} 11\right)$ Las Palmas de Gran Canaria (Spain), April 2011.

Mensah, A.F. and Dueñas-Osorio, L. (2014) 'Improved reliability of wind turbine towers with tuned liquid column dampers (TLCDs)', Structural Safety, Vol. 47, pp.78-86.

Moeller, T. (1997) 'Blade cracks signal new stress problem', WindPower Monthly, Vol. 25.

Murtagh, PJ. and Ghosh, A. and Basu, B. and Broderick, BM. (2008) 'Passive control of wind turbine vibrations including blade/tower interaction and rotationally sampled turbulence', Wind Energy, Vol. 11, No. 4, pp.305-317.

Namik, H. and Rotea, M. and Lackner, M. (2013) 'Active structural control with actuator dynamics on a floating wind turbine.', In 51 st AIAA Aerospace Sciences Meeting Including the New Horizons Forum and Aerospace Exposition, pp.455-470. 
Vibration Control of Wind Turbines: Recent Advances and Emerging Trends 23

Namik, H. and Stol, K. (2010) 'Individual blade pitch control of floating offshore wind turbines. ', Wind Energy, Vol. 13 , No. 1, pp. 74-85.

Namik, H. and Stol, K. (2013) 'Individual blade pitch control of a spar-buoy floating wind turbine. ', IEEE transactions on control systems technology, Vol. 22 , No. 1, pp. 214-223.

Namik, H. and Stol, K. (2011) 'Performance analysis of individual blade pitch control of offshore wind turbines on two floating platforms. ', Mechatronics, Vol. 21 , No. 4, pp. 691-703.

Ollgaard, Borge and Jensen, Soren P. (2017) 'Wind turbine tower having a damper', US Patent 9,657,717, May 2017.

Ollgaard, Borge and Jensen, Soren P. (2017) 'Method of damping wind turbine tower oscillations.', US Patent 9,683,556, June 2017.

Ren, Y., Li, L., Brindley, J. and Jiang, L. (2016) 'Pitch control for wind turbine systems using optimization, estimation and compensation. ', Control Engineering Practice, Vol. 50 , pp. 84-94.

Sarkar, S. and Chakraborty, A. (2018) 'Optimal design of semiactive MRâŁłTLCD for alongâłłwind vibration control of horizontal axis wind turbine tower.', Structural Control and Health Monitoring, Vol. 25, No. 2, p.e2083.

Schlipf, D., Schlipf, D.J. and Kühn, M. (2013) 'Nonlinear model predictive control of wind turbines using LIDAR. ', Wind Energy, Vol. 16 , No. 7, pp. 1107-1129.

Schuler, S., Schlipf, D., Cheng, P.W. and Allgöwer, F. (2013) ' $\ell_{1}$-Optimal Control of Large Wind Turbines. ', IEEE Transactions on Control Systems Technology, Vol. 21, No. 4, pp.1079-1089.

Si, Y. and Karimi, H.R. (2014) 'Gain scheduling $H_{2} / H_{\infty}$ structural control of a floating wind turbine.', IFAC Proceedings Volumes, Vol. 47, No. 3, pp.6788-6793.

Si, Y. and Karimi, HR. and Gao, H. (2014) 'Modelling and optimization of a passive structural control design for a spar-type floating wind turbine', Engineering Structures, Vol. 69, pp.168-182.

Si, Y. and Karimi, H. R. and Gao, H. (2013) 'Modeling and parameter analysis of the OC3hywind floating wind turbine with a tuned mass damper in nacelle', Journal of Applied Mathematics

Simbolotti, G. and Kempener, R. (2016) 'Wind Energy: technology brief', IRENA.

Staino, A. and Basu, B. and Nielsen, S.R.K. (2012) 'Actuator control of edgewise vibrations in wind turbine blades. ', Journal of Sound and Vibration, Vol. 331, No. 6, pp.1233-1256.

Staino, A. and Basu, B. (2013) 'Dynamics and control of vibrations in wind turbines with variable rotor speed.', Engineering Structures, Vol. 56, pp.58-67.

Staino, A. and Basu, B. (2015) 'Emerging trends in vibration control of wind turbines: a focus on a dual control strategy.', Philosophical Transactions of the Royal Society A: Mathematical, Physical and Engineering Sciences, Vol. 373, No. 2035, p. 20140069. 
Staino, A., Basu, B. and Basu, M. (2014) 'Suppression of grid fault-induced vibration in wind turbines using UPQC. ', In 2014 IEEE 5th International Symposium on Power Electronics for Distributed Generation Systems (PEDG), June 2014, pp.1-8.

Stewart, GM. and Lackner, MA. (2013) 'Offshore wind turbine load reduction employing optimal passive tuned mass damping systems', IEEE transactions on control systems technology, Vol. 21, No. 4, pp.1090-1104.

Stewart, GM. and Lackner, MA. (2014) 'The impact of passive tuned mass dampers and wind-wave misalignment on offshore wind turbine loads', Engineering Structures, Vol. 73 , pp.54-61.

Sun, C. (2018) 'Semi-active control of monopile offshore wind turbines under multihazards.', Mechanical Systems and Signal Processing, Vol. 99, No. 2, pp.285-305.

Thomsen, K. and Petersen, JT. and Nim, E. and Øye, S. and Petersen, B. (2006) 'A method for determination of damping for edgewise blade vibrations', Wind Energy, Vol. 3, No. 4, pp.233-246.

Yuan, Y. and Tang, J. (2017) 'Adaptive pitch control of wind turbine for load mitigation under structural uncertainties. ', Renewable Energy, Vol. 105 , pp. 483-494.

Zhang, Z., Nielsen, SRK., Blaabjerg, F. and Zhou, D. (2014) 'Dynamics and control of lateral tower vibrations in offshore wind turbines by means of active generator torque.', Energies, Vol. 7, No. 11, pp. 7746-7772.

Zhang, Z. and Li, J. and Nielsen, SRK. and Basu, B. (2014) 'Mitigation of edgewise vibrations in wind turbine blades by means of roller dampers', Journal of Sound and Vibration, Vol. 333, No. 21, pp.5283-5298.

Zhang, Z. and Nielsen, SRK. and Basu, B. (2015) 'Nonlinear modeling of tuned liquid dampers (TLDs) in rotating wind turbine blades for damping edgewise vibrations', Journal of Fluids and Structures, Vol. 59, pp.252-269.

Zhang, Z. and Staino, A. and Basu, B. and Nielsen, SRK. (2016) 'Performance evaluation of full-scale tuned liquid dampers (TLDs) for vibration control of large wind turbines using real-time hybrid testing.', Engineering Structures, Vol. 126, pp.417-431.

Zhang, Z. and Basu, B. and Nielsen, SRK. (2015) 'Tuned liquid column dampers for mitigation of edgewise vibrations in rotating wind turbine blades', Structural Control and Health Monitoring, Vol. 22, No. 3, pp.500-517.

Zuo, H. and Bi, K. and Hao, H. (2017) 'Using multiple tuned mass dampers to control offshore wind turbine vibrations under multiple hazards. ', Engineering Structures, Vol. 141, pp.303-315. 